\title{
Tecnologias gerenciais, educação e capital
}

\author{
RAFAEL RODRIGO MUELLER \\ Universidade do Extremo Sul Catarinense
}

Antes de construirmos carros, nós construímos pessoas. Lema da Toyota Motors Company

A tecnologia gerencial contemporânea tem com a educação uma relação bem mais estreita e intensa que as primeiras teorias da administração.

Gurgel, 2003, p. 25

\section{ELEMENTOS INTRODUTÓRIOS}

A relação entre educação e formação tornou-se cada vez mais estreita e imersa na ideologia de mercado promovida pelo neoliberalismo, com maior intensidade na década de 1990, às instituições de ensino, principalmente públicas (Laval, 2004). Os massivos investimentos destinados à educação formal, principalmente nos países em desenvolvimento, pelos órgãos multilaterais são indicativos reais da necessidade, verificada a partir da década de 1970 e intensificada na década de 1990, de desenvolver e preparar o que ficou amplamente divulgado como sendo "capital humano", conceito que foi fetichizado e absorvido pela educação e pelas empresas, mas que de fato se desvela como sendo um conjunto de instrumentos subjetivos (tais como raciocínio lógico, aprendizagem, motivação, liderança) e objetivos (como treinamento, qualificação, formação profissional, entre outros) necessários à força de trabalho para uma configuração de sistema produtivo distinta da que se desenvolvera até então.

Conceitos-chave como liderança participativa, motivação, trabalho em equipe, desenvolvimento e aperfeiçoamento de competências e habilidades, ou seja, o controle sobre o trabalho cooperado no interior das organizações, que, como veremos, é uma das características das tecnologias gerenciais, são fatores inerentes 
ao sistema conhecido como "treinamento dentro da indústria" (Training Within Industry - TWI) e que historicamente se consolidou de modo concreto na produção capitalista dos últimos trinta anos a partir do sistema Toyota de produção. ${ }^{1}$ Os elementos históricos que inter-relacionam os modelos de produção citados são analisados no decorrer de nossa pesquisa com o intuito de demonstrar as bases conceituais e ideológicas que sustentam os pilares da educação para o século XXI, quando a tecnologia, ou mais propriamente a aplicação tecnológica da ciência, manifesta seu papel determinante para a efetividade concreta de valorização do valor.

Ante o exposto, torna-se necessária a investigação da relação existente entre as ferramentas utilizadas para a formação do trabalhador dentro de uma nova configuração no sistema de produção e as tecnologias, em especial as gerenciais, desenvolvidas para o controle e racionalização da força de trabalho, pois conforme Denise Pereira e Helena Crivellari (1991, p. 95), "para a reorganização dos processos produtivos, um aspecto essencial e exaustivamente colocado em discussão, é a necessidade de se compatibilizar a gestão da força de trabalho e a tecnologia, tendo em vista a recomposição orgânica do capital”.

\section{O TWI NOS ESTADOS UNIDOS DA AMÉRICA (EUA)}

De acordo com Jim Huntzinger (s.d., p. 4), “o Training Within Industry (TWI) foi iniciado em 1940 durante a Segunda Guerra Mundial com o intuito de aumentar a produção para suprir as necessidades do esforço de guerra das Forças Aliadas". ${ }^{2}$ Ainda segundo o autor:

O TWI foi lançado em 1940 pela National Defense Advisory Commission (NDAC) e eventualmente foi transferido para Federal Security Agency (FSA), com o objetivo de funcionar como parte da nova War Manpower Commission (WMC) no dia 18 de abril de 1942. O TWI continuaria sob o comando do WMC até que suas operações cessassem, fato que ocorreu em setembro de 1945. (idem, p. 6)

Após a queda da França, em 1940, as Forças Aliadas perceberam a urgência de suprir as demandas geradas pela guerra, sendo que os níveis produtivos tinham se

1 Não consideramos o sistema Toyota de produção, ou mais propriamente o toyotismo, como sendo o último estágio de desenvolvimento do modo de produção capitalista, mas sim, conforme verificado por Giovanni Alves (2011, p. 58): "A partir da crise estrutural do capital e de sua mundialização, o que veio a ser denominado de 'toyotismo' tornou-se o 'momento predominante' do que David Harvey denomina regime de acumulação flexível. O espírito do toyotismo torna-se, naquelas determinadas condições histórico-concretas, um valor universal para o capital em processo".

2 Para mais detalhes sobre o histórico do TWI e sua contribuição para o aumento da produção de artefatos de guerra para abastecer os Estados Unidos da América (EUA) durante a sua participação na Segunda Guerra Mundial, ver o segundo capítulo da obra de Donald Dinero (2005). 
elevado em demasia. O governo americano decidiu, então, já prevendo sua possível intervenção direta no conflito, dar início a um programa que poderia solucionar os problemas advindos de uma superprodução de insumos de guerra:

O TWI Service começou a operar visando o [sic] aumento na produção para atender à demanda gigantesca que estava encobrindo as fábricas. Foi focado nas empreiteiras de guerra e outros fabricantes necessários para suprimentos de guerra, que continuaram a crescer em número de companhias transformadas para a produção de guerra. (Huntzinger, s.d., p. 6)

A partir de sua criação, o TWI foi se desenvolvendo em uma rede nacional liderada por profissionais da indústria no intuito de ensinar técnicas de produção às empresas fabricantes de insumos de guerra. Nesse grupo havia empresários voluntários que cediam suas companhias, haja vista a necessidade de efetuar o treinamento "dentro da indústria" com o objetivo de concretizar e legitimar as ações realizadas pelo TWI - empreitada realizada somente em empresas cujo aceite tivesse sido espontâneo pelas gerências de fábricas.

A metodologia do TWI teve como base os métodos de treinamento de Charles Allen, em 1919, desenvolvidos a princípio para a indústria naval americana durante a Primeira Guerra Mundial. Desses métodos, chamados de os "quatro passos de Allen", surgiram os "Programas J": instrução de trabalho (job instruction, JI); métodos de trabalho (job methods, JM); relações de trabalho (job relations, JR); e o desenvolvimento de programa (program development). O elemento-chave desses programas era o inter-relacionamento entre os supervisores e os trabalhadores operários, sendo considerado o fator responsável pelo sucesso da indústria de suporte à guerra dos EUA.

O foco do TWI passou a ser as necessidades dos supervisores na organização e controle da mão de obra, pois a demanda produtiva obrigava as empresas a contratarem um grande número de pessoas não qualificadas, algo que realçava ainda mais o papel fundamental do supervisor e sua relação com os funcionários no que se referia ao aumento da produtividade ${ }^{3}$ industrial americana.

A segunda etapa do processo de desenvolvimento do TWI, a fim de ampliar os níveis produtivos gerados pelo trabalho cooperado, centrou-se na concepção de métodos de ensino que privilegiassem a relação entre supervisores e subordinados e, principalmente, em como alinhar uma vasta gama de habilidades desenvolvidas e não desenvolvidas pelos funcionários das empresas empenhadas com a produção da Segunda Guerra. O trabalho desenvolvido por Charles Allen foi fundamental para a próxima etapa do TWI nos EUA. Conforme citado por Allen (apud Huntzinger, s.d., p. 10):

3 Conforme demonstraremos adiante, a relação supervisor-funcionários, ou mais propriamente a utilização de tecnologias gerenciais por parte dos primeiros, será um dos princípios básicos para o sucesso do sistema Toyota de produção. 
Cada lição completa de ensinamento requer 4 passos ou operações de treinamento conhecidos como passo 1 - Preparação, passo 2 - Apresentação, passo 3 - Aplicação e passo 4 - Teste (ou Inspeção). Esses passos são sempre lecionados nessa ordem dada. O propósito do passo 1 é deixar o aluno preparado para aprender, do passo 2 é instruí-lo, do passo 3 é verificar se há erros e do passo 4 é fazer uma inspeção final na Instrução de Trabalho.

Podem-se verificar, com o método "quatro passos de Allen", as raízes do que se difundiu amplamente, em especial a partir da década de 1990, tanto nas organizações como nos ambientes educacionais: o princípio do "aprender a fazer" (Delors, 2003). Tal conceito se verifica como elemento constante em literaturas da área de educação, fundamentando pesquisas e estudos (Bruno, 1996; Duarte, 2001, 2004; Martins, 2004; Roesler, 2007); e, por ser interdependente ideologicamente em sua manifestação concreta, evoca uma atenção diferenciada aos métodos de ensino utilizados pelos profissionais da educação formal e da educação profissional: a educação para o trabalho e no local de trabalho.

Nesse caso, torna-se necessário explicitar os fundamentos do TWI enquanto uma metodologia de racionalização da força de trabalho efetivada por meio da qualificação profissional diretamente relacionada à formação dos trabalhadores.

\section{A METODOLOGIA DO TWI}

Um dos fatores diferenciais da metodologia concebida e desenvolvida por Allen foi o tratamento dado à questão do treinamento, apontando, valendo-se de pesquisas empíricas realizadas no interior das indústrias, quais os gastos relacionados à falta de um programa de treinamento (desperdício de recursos financeiros, materiais e "humanos") e indicando os três fatores primordiais para a melhor eficiência dos processos de produção:

[...] o instrutor, porque é através de instrução eficaz que podemos assegurar eficiência em treinamento. $\mathrm{O}$ homem, porque quando corretamente treinado, ele faz o melhor trabalho. O serviço, porque eficiência produtiva vem de homens bem treinados [...]. (Allen apud Huntzinger, s.d., p. 11)

Para que se estabelecesse o melhor desempenho do treinamento, era imprescindível que se aplicassem quatro princípios: 1) o ajuste dos padrões; 2) o estabelecimento de instrução correta; 3) o treinamento de maneira contínua dentro das organizações; e 4) esse treinamento não poderia se dar em um curto espaço de tempo. Grande parte do livro de Allen sobre o estudo do treinamento dentro das indústrias foi dedicada a demonstrar como uma metodologia eficientemente aplicada pode contribuir de maneira decisiva para a relação entre instrutores bem selecionados e orientados e uma mão de obra desperta à necessidade de "aprender a aprender".

As preocupações de Allen - no que se referia ao desenvolvimento de uma metodologia orientada para resultados, à seleção e formação de instrutores e à 
necessidade de "despertar" o trabalhor-aluno para a necessidade de se manter em constante atualização para um melhor "aprender a fazer" - em nada diferem das preocupações verificadas nos meios acadêmico e empresarial atualmente no que tange às novas perspectivas acerca da educação e formação profissional dos trabalhadores, respectivamente. De fato, o que Allen desenvolveu em termos de estudos sobre melhores práticas gerenciais orientadas à racionalização da organização do trabalho são os preceitos lógico-práticos do que passou a ser conhecido como "os quatro pilares para a Educação do século XX” (Delors, 2003) e um currículo escolar orientado para o desenvolvimento de habilidades e competências.

\section{"APRENDER FAZENDO": O CONTEÚDO DOS CURSOS TWI}

Intencionalmente, os idealizadores do $\mathrm{TWI}^{4}$ utilizaram-se do método dos "quatro passos de Charles Allen": de acordo com Huntzinger (s.d.), Kane era membro da Emergency Fleet Corporation de Allen, e Dooley e Dietz faziam parte do Departamento de Guerra e conheciam Kane e Allen. As preocupações de Allen no que se referia ao melhor desempenho dos instrutores já tinham sido discutidas no Training Within Industry Report 1940-1945, no qual a questão do “aprender fazendo" foi central. Nesse caso, estabeleceu-se que todo instrutor possuía cinco necessidades: 1) saber o trabalho; 2) ter conhecimento da responsabilidade; 3) habilidade de instruir; 4) habilidade em aperfeiçoar os métodos; e 5) habilidade em liderar. As duas primeiras eram consideradas de responsabilidade da empresa no sentido de fornecer as condições necessárias para o desempenho da função em termos estruturais e de explicitar sua política interna e planejamento; e as três últimas eram providenciadas pelo TWI com seus respectivos "Programas J" (job instruction, job methods, job relations) combinados ao método dos quatro passos de Allen.

\section{INSTRUÇÃO DE TRABALHO (JOB INSTRUCTION)}

Era constituído de cinco sessões, com duas horas de duração cada uma; as duas primeiras sessões tratavam exclusivamente da apresentação e discussão do método de instrução, e as três últimas eram utilizadas para a aplicação prática das apresentações e discussões. O objetivo era de que no decorrer das três últimas sessões os alunos-instrutores utilizassem um método de instrução aplicado com os funcionários de seu departamento e a partir dessa aplicação registrassem e discutissem a experiência com os participantes das sessões. O programa instrução de trabalho, assim como o próprio TWI e todos os outros programas, não foi oficialmente implantado nas empresas até que fosse exaustivamente testado, avaliado e revisado.

4 De acordo com Huntzinger (s.d., p. 8): “O TWI Service foi liderado por Quatro Cavaleiros, que assim ficaram conhecidos durante a $2^{\text {a }}$ Guerra Mundial: Channing Rice Dooley, Diretor do Serviço TWI; Walter Dietz, Diretor Associado; Mike Kane, Diretor Assistente e William Conover, Diretor Assistente”. 
O JI foi desenvolvido com a observação de sua aplicação em várias empresas e aprimorado por meio dos feedbacks destas aliados a uma autoavaliação acerca da eficiência dos procedimentos e métodos utilizados. O foco central do programa era "instruir operários mais do que 'deixá-los aprender", pois "boa instrução está ajudando as pessoas a aprenderem sem atrapalhar seus métodos de aprendizado. Um ensino fraco pode realmente limitar o aprendizado deles" (Allen apud Huntzinger, s.d., p. 14). Os esforços para aprimorar o programa instrução de trabalho estavam ensejados no aumento da demanda militar, que determinava diretamente a produção das empresas aliada à diminuição do número de operários disponíveis, situação que transformava o treinamento em fator-chave para a solução dos problemas concretos. Conforme Newton Bryan (2008, p. 104),

[...] a ênfase é posta no ensino de operações ou de fases de trabalho já codificados pelos especialistas em métodos, e os conhecimentos tecnológicos resumem-se a algumas regras de como utilizar as ferramentas com o mínimo dispêndio improdutivo do trabalho.

Um dos pontos de destaque do programa foi a produção de cartões de instrução de trabalho, e todos os participantes recebiam um exemplar. $\mathrm{Na}$ frente do cartão estavam explícitos os procedimentos necessários para considerar o trabalhador-instrutor efetivamente preparado para instruir, e no verso estavam os quatro passos de "como instruir".

Ressalta-se, pela última frase no verso do cartão, a responsabilidade dada às habilidades que o instrutor devia necessariamente dispor/desenvolver, principalmente no que diz respeito à constituição da subjetividade da força de trabalho no ambiente produtivo: "Se o aluno não aprendeu, o instrutor não ensinou". Objetivamente, a partir desse treinamento, o supervisor, antigo trabalhador subordinado e resistente às mudanças no status quo produtivo, deve transmitir de maneira adequada os conhecimentos relativos à cada tarefa atribuída a seus subordinados, pois, desse modo, sua função

[...] possibilita a apropriação, pelo capital, do saber incorporado no trabalhador qualificado e o controle gerencial do processo de transmissão dos conhecimentos tecnológicos, que, até então, realizara-se conjuntamente com a transmissão de valores advindos da cultura operária, antagônicos aos objetivos do capital. (idem, ibidem)

\section{MÉTODOS DE TRABALHO (JOB METHODS)}

Conforme exposto por Allen (apud Huntzinger, s.d, p. 15), o objetivo desse programa era "[...] ajudar os supervisores a produzirem maiores quantidades de produtos com qualidade em menos tempo, fazendo o melhor uso da mão de obra, máquinas e material disponível no momento". Nesse caso, tornou-se imprescindível uma redefinição e realinhamento das características do trabalho do supervisor, 
quais fossem: sua missão, qualidades, problemas e objetivos (Bryan, 2008). Convém destacar, com base no objetivo exposto do programa métodos de trabalho, que no cerne do desenvolvimento do TWI e de seus métodos de cunho pragmático se encontra a essência da produção capitalista e, consequentemente, das tecnologias gerenciais, qual seja, a racionalização da produção e da organização da força de trabalho orientados à valorização do valor.

Pela análise dos procedimentos técnicos utilizados na produção de um determinado produto, era solicitado aos participantes do programa em questão que desenvolvessem um novo método mais eficiente e adequado às demandas atuais da empresa. ${ }^{5} \mathrm{O}$ modus operandi do programa métodos de trabalho incorporava:

Elementos da Organização Taylorista do Trabalho e da Ergonomia, fornecendo aos participantes um código para estabelecimento das sequências das operações, noções do estudo de tempo e movimentos e diagramas para organizar o trabalho com o mínimo dispêndio físico. Após a discussão dessa sistemática, é dada ao supervisor a tarefa de projetar o trabalho de seus subordinados. (idem, p. 108)

A ideia era desenvolver nos supervisores habilidades para identificar problemas e implementar melhorias que poderiam ser incorporadas em um novo procedimento técnico. Assim como no programa instrução de trabalho, foi desenvolvida uma cartilha de referência para auxiliar os supervisores durante suas atividades.

Há uma grande similaridade entre os procedimentos desenvolvidos no programa métodos de trabalho e o que ficou conhecido como Kaizen (melhoria contínua), no método de gerenciamento japonês.

\section{RELAÇÕES DE TRABALHO (JOB RELATIONS)}

Esse programa estava fundamentado em desenvolver técnicas para melhoria das relações entre supervisores e subordinados, ou seja, as "relações de trabalho" deveriam ser orientadas para melhorias nas relações sociais no ambiente produtivo. Tendo em vista que, segundo o programa em questão, um bom supervisor é aquele que consegue identificar pequenos problemas antes que se tornem maiores e prejudiciais à produção, esse mesmo procedimento era aplicado também no que se referia a relações humanas no espaço produtivo. Utilizando como matriz novamente o método dos quatro passos, esse programa aplicava o seguinte procedimento: com a apresentação de casos fictícios envolvendo supervisores e operários, o manual orientava os supervisores sobre como cada um deles resolveria os problemas a partir

5 Essa é uma referência direta ao sistema Toyota de produção, particularmente por sua capacidade de "captura ou sequestro" do saber objetivo dos trabalhadores por intermédio de "sugestões espontâneas" feitas por eles mesmos no intuito de melhorar os processos produtivos do sistema. Para uma análise pormenorizada dessa questão, ver Lucídio Bianchetti (2000), José Henrique de Faria (1997, 2004) e Giovanni Alves (2011). 
dessa discussão eles deveriam aplicar em seus respectivos departamentos as lições obtidas e posteriormente apresentar os resultados gerados para o grande grupo.

De acordo com Bryan (2008, p. 104), o programa relações de trabalho era "uma síntese das descobertas da psicossociologia do trabalho americana, desenvolvida com base na constatação da fragilidade dos pressupostos tayloristas quanto às motivações dos trabalhadores". Apesar de outros teóricos terem desenvolvido pesquisas no campo organizacional, tendo a mesma preocupação e orientação do TWI, como Chester Barnard e Douglas McGregor, foi Elton Mayo quem mais contribuiu para o "enfoque das relações humanas nas organizações", tendo como pressuposto teórico a organização científica do trabalho desenvolvida por Taylor (idem, ibidem):

A Escola das Relações Humanas surge numa época em que se funda o sindicalismo vertical, por indústria, em substituição ao de ofícios. Cabe ao conselheiro das relações humanas [supervisor, gerente] a supressão das resistências informais às exigências administrativas. Enquanto a Escola Clássica pregava a "harmonia" pelo autoritarismo, Mayo procura-a pelo uso da Psicologia, convertendo a resistência em problema de inadaptação pela manipulação dos conflitos, por pessoal especializado em Psicologia social e Sociologia industrial, ou melhor, relações industriais. (Tragtenberg, 1985, p. 83)

De acordo com Geraldo Francisco Filho (2006), o pragmatismo de John Dewey e a psicologia dinâmica de Kurt Lewin foram imprescindíveis para a afirmação das ideias de Mayo.

Como nos demais programas, para facilitar a aplicação e orientar os supervisores, desenvolveu-se um cartão para relações de trabalho como referência.

\section{DA MÁQUINA AO HOMEM: O DETOUR TECNOLÓGICO NAS ORGANIZAÇÕES VIA TECNOLOGIAS GERENCIAIS}

No decorrer de nossa análise sobre a relação do desenvolvimento histórico entre o programa TWI e o sistema de produção japonês (ou, mais propriamente, o sistema Toyota de produção), pôde-se verificar a importância que ambos atribuíram à formação do instrutor/supervisor numa perspectiva de ampliar a racionalização da produção (processos, operações, métodos e técnicas) pela organização e controle da produção e da força de trabalho, e não necessariamente nesse percurso tenha sido dada a ênfase na tecnologia física como o taylorismo/fordismo dava a essa manifestação de tecnologia. Por sua vez, pôde-se constatar que o sistema Toyota de produção, como um estágio mais aprimorado e avançado do programa TWI - na abrangência produtiva -, utilizou-se, em grande parte para o seu próprio desenvolvimento, de tecnologias gerenciais ao desenvolver inovações organizacionais que atuassem diretamente sobre o controle da força de trabalho e na potencialidade existente na intensificação da produtividade. 
O modo pelo qual o referido sistema produtivo constituiu-se baseado em suas especificidades técnicas está, certamente, relacionado com as determinações históricas que o conduziram para sua perspectiva de valorização do valor, como por exemplo: a condição econômica e social do Japão após a Segunda Guerra, que motivou os países aliados, capitaneados pelos EUA, a transformar o referido país em um "laboratório" ou centro de pesquisas industriais; os seus limites geográficos que inviabilizavam a produção em larga escala com seus estoques, tanto de matérias-primas como de produtos acabados; a constituição dos sindicatos "patronais" - por empresas - em substituição aos sindicatos classistas - por setores da economia - vinculados ao agora extinto Partido Comunista; e, talvez, um dos fatores históricos determinantes, a condição econômica dos EUA e sua determinação sobre a produção, que não permitia vislumbrar, em curto e médio prazos, quaisquer modificações técnicas ou inovações organizacionais em sua planta industrial, que naquele momento estava em plena ascensão. Tais fatores moldaram o sistema produtivo das indústrias japonesas naquele período histórico (o pós-guerra), o que, $a$ posteriori, se concretizou como sendo o sistema Toyota de produção.

Foi especificamente na referida empresa automotiva (Toyota), constituída naquele momento de extrema escassez, que as inovações criadas por engenheiros americanos tiveram seu espaço criativo ilimitado e, aliadas à percepção de Taiichi $\mathrm{Ohno}^{6}$ e aos determinantes inerentes ao Japão (cultura, tradição, costumes etc.), conjugaram-se a ponto de se transformarem em um sistema produtivo orgânico.

Tais inovações estavam embasadas na prerrogativa de que necessariamente deviam estabelecer um ambiente que privilegiasse a racionalização da produção, porém não mais focado nas características propostas pelo sistema de produção tipicamente americano (de base taylorista-fordista), mas nas circunstâncias concretas que determinavam o Japão naquele momento: a completa escassez de recursos, matérias-primas e parques industriais. Ou seja, o foco deveria estar no desenvolvimento de métodos e técnicas que restringissem a praticamente "zero" quaisquer possibilidades de permanência de elementos constituintes do processo produtivo que gerassem custos desnecessários, por exemplo: estoques, retrabalho por falta de padronização, as perdas e os desperdícios etc. ${ }^{7}$ Nesse caso, para a efetivação de tal intento era necessária e fundamental a utilização dos conhecimentos provenientes

6 Taiichi Ohno (1912-1990) é considerado o pai do sistema Toyota de produção e do kanban. Formou-se em engenharia mecânica na Escola Técnica de Nagoya e entrou para a Toyota Spinning and Wearing em 1932. Em 1943 foi transferido para a Toyota Motor Company, tornou-se diretor em 1954, diretor gerente em 1964, diretor gerente sênior em 1970 e vice-presidente executivo em 1975.

7 Faz-se necessário destacar que a racionalização da produção e do trabalho não foi criação ou exclusividade do sistema Toyota de produção, pois o controle de detecção e extinção do que José Ricardo Tauile (2001) denomina como "porosidade do trabalho" - ou seja, o trabalho que não agrega valor direto ao produto, como paradas para o café, idas ao banheiro etc. - já era motivo de preocupação tanto para os engenheiros industriais do século XIX, quanto para Taylor e Ford; porém, a criação de novas tecnologias gerenciais que atuassem diretamente sobre a intensificação da força de trabalho, 
da realidade empírica vivenciada pela força de trabalho no seio da produção e, consequentemente, do realinhamento de sua formação; destarte, os maciços investimentos em treinamento teriam certamente de providenciar tal condição favorável ao sistema de produção em questão.

Tal prerrogativa está em total consonância com a afirmação feita por Marx (Marx; Engels, 1992, p. 79) ao questionar: "Qual é o custo de produção da própria força de trabalho? É o custo necessário para conservar o operário como tal e educá-lo para este ofício". Com base nessa citação, podemos identificar dois fatores de real importância para o delineamento de nossa pesquisa: 1) para Marx, o adiantamento de capital com intuito de formar a força de trabalho é considerado como "custo necessário", ou seja, havia uma necessidade de tal adiantamento por ser o trabalho elemenento fundamental para a valorização do valor; 2) o sentido empregado por Marx para "educação" como um realinhamento dos conhecimentos técnicos provenientes de todos os componentes do trabalho na produção. Essa era a significância que a educação deveria ter a partir de sua constituição no e pelo capitalismo, ou seja, de maneira alguma esses dois fatores poderiam contribuir para uma formação omnilateral, prevista por Marx, que aliasse o conhecimento técnico ao conhecimento científico.

A redução do termo "educação", como sendo somente a formação da força de trabalho na produção, terá consequências fundamentais, principalmente para o direcionamento das reformas educacionais propostas com maior intensidade a partir do século XXI e determinadas pelos ideais do capitalismo globalizado e que aprofundaremos a seguir. Aqui nos deteremos a indicar de que maneira essa perspectiva acerca da educação serviu como pressuposto ideológico para o desenvolvimento das tecnologias gerenciais inerentes ao sistema Toyota de produção. Conforme Eneida Shiroma (1993), a formação de trabalhadores polivalentes no espaço de fábrica foi a base do modelo japonês, e essa formação exerce maior influência e goza de maior prestígio ante a educação formal. A autora (idem,p. 50) enfatizou também a importância de os funcionários recém-admitidos "passarem por programas consecutivos de indução e capacitação para serem moldados internamente à empresa, fazendo com que sejam vultuosos os investimentos de educação do trabalho":

Durante o rápido desenvolvimento industrial do Japão nos anos [19]50 e [19]60, havia carência de mão de obra, e os formandos do secundário passaram a ser altamente cobiçados pela indústria que lhes forneceria uma educação complementar. O currículo consistia em $70 \%$ de treinamento prático sobre o ofício e $30 \%$ sobre cultura geral. Durante os 3 anos de curso eram ensinadas não apenas as habilidades mas também a cultura da empresa [...]. Recebiam formação geral exaustiva sobre a firma, sua história, os objetivos da direção e o comportamento exigido para o trabalho. (idem, p. 51)

concebendo índices de produtividade inalcançáveis pelo taylorismo/fordismo, certamente foi o grande diferencial do sistema implementado na e pela Toyota Motors. 
Ao destacarmos como o referido sistema de produção "inverteu" a ordem de importância dos recursos disponíveis, ao colocar o trabalhador e sua relação com a administração com ênfase na formação no e pelo trabalho produtivo, queremos enfocar também a importância das tecnologias gerenciais como forma de controle e de organização social da produção. Nesse caso, a reorientação funciona como um desvio da "ordem natural" imposta pelo sistema de produção americano com a excessiva ênfase nas tecnologias físicas (rígidas ou flexíveis) ${ }^{8}$ para atingirem altos níveis de extração de mais-valia. A utilização da própria capacidade inerente a todo ser social, a racionalidade, será direcionada para o desenvolvimento de métodos e técnicas de controle e organização da força de trabalho alinhadas às necessidades atuais do padrão de acumulação vigente. Sendo assim, o sistema Toyota de produção extrapola os limites geográficos da planta industrial japonesa e passa a ser adotado não somente em filiais da mesma empresa em outros países, mas também por outras organizações ocidentais interessadas em atingir os índices de lucratividade decorrentes de sua utilização, e tais índices somente se efetivam quando se "desvia da ordem natural" do sistema de produção americano e implementam-se maciçamente tecnologias gerenciais relacionadas à produção.

Isso de maneira alguma diminui a importância da racionalização da produção obtida por meio das tecnologias físicas, mas significa que as tecnologias gerenciais possibilitam níveis não atingíveis pela primeira no sentido de valorização do valor. Nesse caso, a ordem de importância de priorização de utilização na produção capitalista sofre um detour tecnológico, em que as ciências exatas e naturais deixam de ser a base conceitual no que se refere à aplicação tecnológica da ciência, sendo superadas pelas ciências humanas e sociais no controle do comportamento e alinhamento ideológico da força de trabalho aos preceitos do padrão de acumulação atual. De acordo com Tauile (2001, p. 146):

Nas economias ocidentais modernas, tornou-se progressivamente evidente que a utilização eficaz de novas tecnologias de automação flexível (TAF) dependia em grande parte da introdução de novos e adequados métodos gerenciais. No caso japonês, todavia, cabe ressaltar que as mudanças nas TOSP [Tecnologias de Organização Social da Produção] ${ }^{9}$ precederam à introdução de novas tecnologias de automação flexível.

8 Conforme Tauile (2001, p. 143) “o fordismo, que se apoiava na automação rígida, típica da produção em grande escala de produtos padronizados, começou a encontrar uma forte turbulência gerada pela instabilidade econômica da década de 1970. A difusão de equipamentos de automação flexível, que então começava a se acelerar, não conseguia superar as dificuldades colocadas pelos novos e instáveis padrões de demanda, pois ainda não se compreendia plenamente o que a nova base significava em termos das novas possibilidades de produção".

9 Tauile (2001) atribui às Tecnologias de Organização Social da Produção (TOSP) as mesmas características que damos nessa pesquisa às Tecnologias Gerenciais. 
Foi a partir da década de 1960 que novas TOSPs como o just in time e os Círculos de Controle de Qualidade (CCQs) ganharam amplitude nas plantas industriais japonesas, em que

[...] o sucesso dessa TOSP exigia um elevado grau de coordenação, precisão e qualidade das atividades executadas, tanto dentro da fábrica como no âmbito da articulação entre empresas, até porque, havendo uma dramática redução dos estoques intermediários, as ineficiências do processo tornavam-se incompatíveis com a estratégia produtiva. (Tauile, 2001, p. 149)

As tecnologias gerenciais potencializam a valorização do valor principalmente por meio da redução de custos que podem advir de qualquer elemento da produção: estoques, processos, movimentação, transporte etc. É dessa forma que o conjunto de métodos e técnicas provenientes das tecnologias gerenciais (just in time e kanban) necessariamente extrapola os limites da própria empresa, atingindo também as empresas fornecedoras, que devem equalizar sua produção à demanda da empresa cliente. A perspectiva que envolve as tecnologias gerenciais é a da lean production (produção enxuta), e esta permeia todo o sistema Toyota de produção na medida em que se deve

[...] racionalizar os fluxos de fabricação entre processos de forma contínua, otimizando e aproveitando os espaços disponíveis, a fim de minimizar a movimentação de pessoas, produtos, materiais e documentos. É necessário estabelecer um fluxo racional de trabalho. Quando são aprimorados os processos e elevados os niveis de capacitação e motivação dos empregados, os indices de desperdício caem naturalmente. (Justa; Barreiros, 2009, p. 7, grifos meus)

O elemento que integra todo o sistema Toyota de produção é a forma como utiliza suas tecnologias gerenciais no intuito de racionalizar a produção ad aeternum - e não se pautando como elemento principal em tecnologias físicas que, além de gerarem custos de manutenção e depreciação como capital fixo, não possibilitam a melhoria contínua que se desenvolve com o processo de colaboração horizontal (o trabalho cooperado da força de trabalho) e vertical (o trabalho de controle, aprimoramento e treinamento garantido pelo gerente/instrutor/líder/ condutor) dentro do sistema Toyota de produção. Um exemplo empírico de tal afirmação advém de uma citação de Chappel (apud Battaglia, 2005, p. 1), em que a autora, após visita a Toyota Motor Manufacturing North America situada em Erlanger, Kentucky, destaca que "em um mundo inundado pela logística computadorizada, a Toyota afirma que seus cartões coloridos - kanban - estão gerindo muito bem a cadeia de suprimentos"; e mais adiante destaca:

Enquanto percorria as instalações de Knoxville, um operador de empilhadeira percebe um erro: no meio da área de recebimento, um pallet de caixas destinado a determinada planta é colocado sobre uma pilha que deveria ser destinado a uma outra. $\mathrm{O}$ operador de empilhadeira então se desloca até lá e separa as duas. 
Ele conseguira detectar o erro graças às diferenças nos cartões: eles possuem cores diferentes. $\mathrm{O}$ engano não seria desfeito se tivesse recebido uma ordem computadorizada ou se fosse apenas uma diferença no código de barras. São os cartões. São as pessoas treinadas para olhar e entender os cartões. É o controle visual simples e inequívoco. (Chappel apud Battaglia, 2005, p. 5)

O relato explicita uma das atividades relacionadas às tecnologias gerenciais, observando que estas vão muito além da mera utilização dos sentidos no intuito de detectar e corrigir possíveis erros: é a capacidade de observar os processos, analisá-los e sugerir melhorias - que é, sem dúvida, o maior diferencial dessa tecnologia -, ou seja, o nível de cooperação nesse caso extrapola a divisão imposta pelo sistema de produção americano que restringia o potencial inerente à força de trabalho produtiva, qual seja, uma formação profissional que privilegia a contribuição direta da força de trabalho como fonte de aprimoramento da racionalização da produção.

O caráter "colaborativo" presente no sistema Toyota de produção manifesta-se concretamente com as sugestões propostas pela força de trabalho de implementar melhorias no processo produtivo. Contudo, a colaboração tem de ser assimilada por parte dos trabalhadores por meio de uma formação que privilegie essa característica da produção; e, por ser "flexível" o sistema de produção, a formação e o treinamento dos trabalhadores devem ser contínuos. Nesse caso, a formação da mão de obra no sistema Toyota de produção deve valorizar o desenvolvimento de competências e habilidades que irão propiciar a colaboração por parte dos trabalhadores e serem incentivadas pelos gerentes que, a partir disso, serão líderes que devem "orientar" seus subordinados a trabalharem por meio do trabalho cooperado e colaborativo. Necessariamente, as orientações formativas que se desenvolvem pelo sistema de produção toyotista devem estar orientadas para suas características proeminentes: redução contínua de custos que não agregam valor; e habilidades que vão além da mera instrumentalização, característica do sistema de produção americano. $\mathrm{O}$ desenvolvimento histórico de uma "pedagogia toyotista" e suas raízes ideológicas será analisado a partir do próximo item.

\section{A EDUCAÇÃO NO E PARA O TRABALHO: RELACIONANDO A GESTÃO CAPITALISTA COM A FORMAÇÃO PROFISSIONAL}

É imperativo, no modo de produção capitalista, estruturar a constituição de relações sociais baseadas na relação econômica de custo e benefício. Como vimos no item anterior, para que se desenvolva no seio da produção capitalista programas de formação e treinamento, estes devem ser devidamente mensurados e passíveis de perpetuação pela sua capacidade de providenciar mais-valor em uma perspectiva de crescimento contínuo. Sendo assim, o vislumbre de possibilidades de intensificar a racionalização do trabalho via formação intra e extraorganizacional somente efetiva-se pela análise da relação custo-benefício que está em concomitância com a necessidade intrínseca de o capital valorizar todos os âmbitos da organização 
social. A intervenção direta de órgãos multilaterais que dão sustentação política e ideológica ao construto do capital no que se refere aos diversos loci relacionados à educação formal ou informal e formação profissional ${ }^{10}$ faz com que os processos que se estabelecem por meio da relação entre ensino e aprendizagem devam ser orientados num sentido de mercantilização, reduzindo a educação a mero objeto (moeda) de troca entre capital e trabalho. ${ }^{11}$

Os processos educativos, particularmente estabelecidos na década de 1950 no mundo, determinaram os caminhos percorridos pela educação, os quais se consolidaram com maior efetividade na década de 1990, quando as teorias do capital humano e das competências entraram em consonância com o momento da economia ao final do século XX e já com vistas para o século XXI. Esse momento de transição secular histórica marca também o desenvolvimento dialético no que concerne à superação, incorporando pressupostos teóricos que determinam os parâmetros educacionais e de formação profissional, em que a relação entre a educação formal e o controle sobre a organização do trabalho e sobre os processos produtivos vem de longa data. A Organização para a Cooperação e Desenvolvimento Econômico (OCDE) publica anualmente um documento que trata exclusivamente das perspectivas acerca da educação formal no mundo, e o referido material publicado no início de 2009 aborda, entre outras, as seguintes questões:

- [...] examina a maneira como os sistemas de educação continuam a expandir-se, com um número de titulares de diplomas universitários quase duas vezes maior em 2007 do que em meados dos anos 1990.

- Considerando o actual cenário de recessão econômica - caracterizado pela restrição dos recursos, mas também por uma elevada necessidade de investimentos em capital humano -, a edição de 2009 analisa os processos, o financiamento e os resultados do sector da educação como factores que determinam se os sistemas de educação oferecem uma boa relação custo-benefício. (OCDE, 2009, p. 1 , grifos meus)

Podemos observar que, conforme a OCDE, apesar do momento econômico atual ser de crise, em que necessariamente a racionalização dos recursos deve ser priorizada, os investimentos em "capital humano" permanecem na agenda econômica mundial, observando-se também uma relação direta entre educação e formação de "capital humano", o que consolida os dados "positivos" do referido documento num âmbito puramente quantitativo com base em dados estatísticos. Em essência, o documento Panoramas sobre a educação: indicadores da OCDE se pauta sobre a permanente relação que, de acordo com a perspectiva do capital, deve ampliar-se no

10 Dentro dos quais, atualmente e como demonstramos aqui, o processo de nivelamento entre educação e formação é algo concreto em nossa sociedade nos últimos trinta anos.

11 Cabe ressaltar que os loci de educação formal, em particular os públicos, são espaços "em disputa" pelo capital e pelos atores desses espaços, ou seja, nem toda educação formal determinantemente prevê como seu objetivo-fim a sua mercantilização. 
que se refere aos sistemas educacionais desenvolverem a formação necessária para abastecer uma suposta demanda do mercado mundial em suas diversas atividades profissionais. Nesse sentido, importa destacar que:

A Teoria do Capital Humano é um constructo ideológico e doutrinário que associa trabalho humano a capital físico, ambos tidos como fatores de produção regidos por lógicas de rentabilidade econômica a partir de cálculos utilitaristas de maximização do benefício individual. Sob a alegação de promover as capacidades humanas, esse quadro teórico reforça o domínio ideológico do capitalismo, acirrando a concorrência entre os indivíduos e transferindo, para os trabalhadores, a responsabilidade pela existência das desigualdades no mercado de trabalho. (Cattani; Holzmann, 2006, p. 57)

O construto teórico desenvolvido por Theodore Schultz e Garry Becker, e que teve seu reconhecimento mundial a partir da década de 1970 como um ideal a ser perseguido pelos sistemas educacionais, ainda orienta as perspectivas acerca da educação na primeira década do século XXI, permanecendo o foco principal das análises feitas sobre os sistemas educacionais e, especificamente, sobre a gestão destes, de maneira que se estabelece a necessidade de uma subsunção real do trabalho ao capital - e que atualmente não se dá por meio de tecnologia física, mas principalmente pela "captura ou sequestro" da subjetividade da força de trabalho (Alves, 2007; Faria, 2007) via tecnologias gerenciais, em que tais tecnologias desenvolvem-se e consolidam-se como instrumentos para tal "captura/sequestro", com maior propriedade no sistema Toyota de produção.

Para que a relação custo-benefício existente entre a educação/formação e a produtividade se estabeleça concretamente no plano das relações sociais, é necessário que ela esteja alinhada às necessidades advindas do âmbito da produção capitalista de maneira que os trabalhadores que atuam nessa relação sejam formados de acordo com os seus preceitos teórico-práticos, para possibilitar a racionalização da produção e, consequentemente, a valorização do valor. Assim como no decorrer do século XX, foi necessário que os preceitos da administração científica de Taylor fossem assimilados pelo ambiente escolar como uma "administração escolar" voltada à racionalização do plano produtivo e, a partir da década de 1970, com o advento da reestruturação produtiva, exige-se dos sistemas escolares uma formação alinhada aos novos paradigmas impostos pelo sistema Toyota de produção.

Nesse caso, torna-se necessário o alinhamento entre o sistema de produção e o sistema de educação, conforme previsto na análise de Gramsci sobre o sistema produtivo americano no século XX e o sistema de relações sociais constituintes da superestrutura. De acordo com Ruy Braga (2008, p. 25):

Americanismo e fordismo representam as duas faces da mesma moeda, isto é, uma nova composição das forças produtivas do trabalho social por meio dos chamados processos de modernização conservadora: à racionalização da produção correspon- 
dia um novo ajuste entre estrutura e superestrutura, sempre no sentido de recompor a unidade entre relações sociais de produção e aparelhos de hegemonia.

Podemos estabelecer a mesma associação entre as relações sociais de produção orientadas pelo toyotismo e os aparelhos de hegemonia instituídos para além da organização. Conforme Gramsci (2008, p. 68), há uma necessidade de "adequar os costumes às necessidades do trabalho". A gestão dos sistemas escolares responsáveis pela formação do atual e futuro trabalhador deve estar em consonância com as necessidades psicofísicas impostas pelo sistema toyotista de produção, nesse caso, os princípios que norteiam o referido sistema de produção (redução de custos e formação polivalente) devem ser buscados e estabelecidos na prática pelos sistemas educacionais. Exemplo empírico de tal necessidade dá-se a partir do relato de Jeffrey Liker e Michael Hoseus (2009, p. 93) e que ilustra nossa reflexão:

Mesmo o luxo de escolher a comunidade em que a nova fábrica será construída não é o suficiente para a Toyota. A empresa está acostumada a influenciar a força de trabalho desde antes de começar a contratar as pessoas. No Japão, a Toyota começa o processo de preparar os jovens para entrar em sua cultura por meio de colaboração com o sistema escolar local. Na cidade hoje conhecida como Toyota City, há um sistema de ensino médio da Toyota. Os interesses e aptidões dos alunos são avaliados durante os últimos anos do ensino fundamental, e os estudantes recebem escolhas e indicações que se adaptam às suas competências. Há três carreiras gerais dentro da Toyota: trabalho de produção, trabalho de manutenção especializada (solda, elétrica, programação de robôs, etc.), engenharia. Com base nessas escolhas, é possível escolher três caminhos educacionais distintos. A maioria dos alunos que escolhe trabalhar para a Toyota quando se forma na escola local opta pelo caminho do trabalho de produção. Na Escola de Ensino Médio Toyota, eles vivem em dormitórios e aprendem, trabalham e se divertem juntos. É claro que continuam a aprender as matérias tradicionais, como japonês e aritmética, mas também são expostos ao Modelo Toyota, incluindo aspectos técnicos da construção de carros, os componentes do STP [Sistema Toyota de Produção] e os valores e componentes interpessoais do trabalho em equipe e da cultura Toyota.

É a real orientação de um sistema escolar quase em sua plenitude pelo modelo de produção atual, sem qualquer possibilidade de concessão por parte do primeiro, conforme Liker e Hoseus (idem, ibidem): "quando a Toyota começou sua fábrica no Kentucky, o desenvolvimento de seu próprio sistema escolar formador não era uma opção".

Tendo por base ainda a instalação da fábrica em Kentucky, a relação exemplificada anteriormente no Japão também foi posta em ação nos EUA: após um rigoroso processo de seleção de pessoas para trabalharem na filial, foi constatado que somente $5 \%$ das pessoas avaliadas possuíam as qualidades e habilidades necessárias para se encaixar no "padrão Toyota" de produção, pois "com o tempo a Toyota queria 
mais produtividade, e decidiu colaborar criativamente com a comunidade para aumentar a capacidade dos trabalhadores disponíveis para contratação, semelhante ao que a empresa faz no Japão" (Liker; Hoseus, 2009, p. 94).

Constata-se uma necessidade intrínseca ao sistema de produção em questão de gerir e controlar a formação da força de trabalho e reduzir, por meio do "assalto" aos currículos escolares, os princípios inexoráveis da educação a meros instrumentos de incorporação dos ideais referentes ao seu modo de intensificação da racionalização produtiva. Assim como o próprio sistema Toyota de produção é uma síntese de múltiplas determinações historicamente constituídas, formando-se por meio de referenciais políticos e econômicos mundiais e de condições próprias da cultura japonesa, a relação entre esse sistema e os preceitos educacionais postos para o século XXI também sofre múltiplas influências, principalmente do plano organizacional orientado à valorização do valor via potencialização exponente da racionalização produtiva. Nesse sentido, é preciso verificar até que ponto o programa de treinamento TWI, desenvolvido com base nas necessidades do complexo militar-industrial, ${ }^{12}$ serve de base para a ideologia educacional conhecida como "os pilares” para a educação do século XXI e como o conteúdo de tal ideologia dá sustentação para a consolidação no plano organizacional e educacional das tecnologias gerenciais, tema de nosso próximo item.

\section{AS IMBRICAÇÕES EXISTENTES ENTRE OS QUATRO PASSOS (DO TWI) E OS “QUATRO PILARES” (DA EDUCAÇÃO)}

Pretendemos demonstrar neste item as aproximações e similaridades existentes entre o método dos quatro passos, de Charles Allen, (que serviu de base para o TWI, que consequentemente é a base conceitual do sistema Toyota de produção) e o dos quatro pilares para a educação do século XXI, idealizados por Jacques Delors (que se constituem como a materialização no plano educacional dos ideais de formação da mão de obra no referido sistema produtivo). Nesse caso, há uma relação do desenvolvimento histórico existente entre o método dos quatro passos, o TWI e os quatro pilares para a educação como projetos de introjeção dos ideais previstos para o novo padrão produtivo que adquire uma abrangência global nos últimos trinta anos. Os programas são formas de implementação na produção da racionalidade do capital, que implicam mudanças e transformações na formação profissional da força de trabalho. Particularmente, as ideias previstas no conjunto dos programas aqui analisados por si sós não impõem uma intervenção direta na realidade, tendo que inevitavelmente serem materializadas por intermédio de agentes "treinados" para tal intento, ou seja, a perspectiva de busca de uma racionalização na produção capitalista deve ser objetivada com a intervenção de seus executores,

12 Para mais informações, ver o item 16.2, intitulado "O significado do complexo militar-industrial”, presente na obra de István Mészarós (2002). 
que no caso podem ser desde gestores organizacionais até pessoas com cargos de comando e gestão na educação, como os professores.

Um dos primeiros elementos que podemos constatar no que diz respeito à aproximação e similaridade fica por conta do item "preparação", referente ao método dos quatro passos e o primeiro pilar "aprender a conhecer" de Delors: a "preparação" tem em sua definição o fato de haver uma necessidade de sensibilizar o trabalhador em formação para o ato de aprender e que, para tal intento, o conhecimento novo deve ser "ancorado" em um preexistente; situação muito próxima conceitualmente do que propõe o "aprender a conhecer", que privilegia "o domínio dos próprios instrumentos do conhecimento" (Delors, 2003, p. 90) ante a necessidade de saberes específicos. O pilar "aprender a fazer" é a síntese do que é preconizado pelos "Programas J" do TWI e pelo item "aplicação" dos quatro passos: a importância de desenvolver-se um conjunto de habilidades e competências - particularmente com professores/instrutores - que supram as necessidades de um novo paradigma produtivo. Mesmo que os "Programas J" estivessem pautados em uma base taylorista/ fordista, a racionalidade que permeia historicamente a relação entre ambos é a de se obter um controle sobre a formação da mão de obra indispensável para a perpetuação de qualquer sistema produtivo, saindo dessa forma de um controle sobre tempos e movimentos, e passando para o controle de competências e habilidades que estimulam a utilização da subjetividade humana no ambiente produtivo. Necessariamente, Delors (idem, p. 94) indica que há uma relação entre o pilar "aprender a fazer" com o sistema Toyota de produção ao afirmar que:

O aumento de exigências em matéria de qualificação, em todos os níveis, tem várias origens. No que diz respeito ao pessoal de execução, a justa posição de trabalhos prescritos e parcelados deu lugar à organização em "coletivos de trabalho" ou "grupos de projeto", a exemplo do que se faz nas empresas japonesas: uma espécie de taylorismo ao contrário.

O "aprender a viver juntos" tem em sua concepção uma aproximação ao que foi proposto por um dos itens dos "Programas J", chamado "relações de trabalho": a criação e implementação de um conjunto de técnicas e métodos que estimulem o convívio harmonioso entre e intraníveis hierárquicos, e o trabalho cooperado por meio de objetivos comuns previstos tanto para a produção como para a organização como um todo. O controle sobre as relações sociais no ambiente produtivo é uma condição fundamental e que foi pensada e viabilizada desde os quatro passos até os "quatro pilares", e nestes o objetivo econômico central foi mascarado por objetivos "humanizadores" previstos para a educação no século XXI. Esse controle passa necessariamente pelo expurgo e anulação da produção de organismos incentivadores da não conciliação dos objetivos da força de trabalho aos objetivos empresariais, como os sindicatos e os partidos políticos, sendo o Japão pós-guerra, o caso primordial de 
tal condição. ${ }^{13}$ Os itens "teste" e "aprender a ser" aproximam-se por se tratarem de sínteses dos itens componentes de cada proposta de formação, previstas nos quatro passos e nos "quatro pilares", respectivamente.

Analisando o encadeamento histórico dessas propostas, constata-se que é dada à formação profissional e à educação, como fontes de desenvolvimento das capacidades físicas e cognitivas, poderes que ultrapassam as suas condições ontológicas no que se refere às possibilidades reais de estabelecer-se uma relação direta entre o aumento da qualificação profissional e o desenvolvimento econômico e social em uma perspectiva generalizante, enveredando dessa forma para um caminho contrário à lógica imposta pelo capital.

\section{CONSIDERAÇÕES FINAIS}

Conforme evidenciado em nosso estudo, as tecnologias gerenciais, enquanto uma manifestação da aplicação tecnológica das ciências, em especial das ciências humanas e sociais, e como instrumentos para apropriação objetiva e subjetiva dos produtos da força de trabalho, objetivam-se na materialidade em contraposição

[...] aos operários individuais, de forma autônoma, como um ser alheio, objetivo, que lhes preexiste, que está ali sem o seu concurso e amiúde contra o seu concurso, como meras formas de existência dos meios de trabalho que os dominam e são independentes deles, na medida em que essas formas (são) objetivas. (Marx, 1985, p. 127)

Torna-se importante realçar as características que indicam uma situação de continuidade e descontinuidade existente entre os sistemas de produção, ${ }^{14}$ observando-se principalmente as aproximações pelo enfoque das relações humanas e pelos métodos e técnicas de controle sobre os processos produtivos concebidos nos EUA e implantados no Japão por engenheiros americanos, além da referência constante à Ford que Ohno (1997), o pai do sistema Toyota de produção, faz em sua principal obra.

No que se refere à educação, o processo de continuidade e descontinuidade presente na relação existente entre o sistema taylorista/fordista e o sistema Toyota de produção pode ser observado em nossa análise acerca do desenvolvimento histórico existente entre o método dos quatro passos de Charles Allen, o TWI, o modelo de gerenciamento no sistema Toyota de produção e os princípios elencados pelos "quatro pilares para a educação do século XXI” de Jacques Delors. O fio condutor que interliga todos esses métodos e orientações é a racionalização necessária à valorização do valor, que necessita se apropriar dos nexos causais existentes na relação entre trabalho e

13 Para um maior aprofundamento dessa questão, ver Eurenice de Oliveira (2004).

14 Para uma análise mais aprofundada sobre o processo de continuidade e descontinuidade existente entre o sistema taylorista-fordista e o sistema Toyota de produção, ver as obras de Giovanni Alves (2011) e Geraldo Augusto Pinto (2011). 
educação, na qual a subsunção real do trabalhador não é suficiente para que os níveis de extração de sobrevalor se mantenham em um patamar aceitável, pois este vem se desenvolvendo para que haja a subsunção total do ser social ao capital.

Para tanto, o controle deve se manifestar objetiva e subjetivamente tanto no espaço da fábrica quanto no espaço educacional (quando ambos não se encontram sobre o mesmo teto). Nesse caso, torna-se imprescindível a utilização de métodos, técnicas e princípios orientadores que dão sustentação ideológica para o processo de subsunção total do ser ao capital, providenciando a relação direta entre trabalho e educação determinada pela valorização do valor. Historicamente, essa relação evidencia-se pelo enfoque das relações humanas, em que a aplicação tecnológica das ciências humanas e sociais tem uma contribuição determinante para a manipulação da força de trabalho por meio do controle, não somente o pautado na coerção, mas principalmente em elementos de persuasão, característica fundamental observada no desenvolvimento das tecnologias gerenciais.

Sendo assim, independente da "forma" pela qual os preceitos da subsunção total do ser ao capital se manifestem - seja por meio dos quatro passos, do TWI, do gerenciamento toyotista ou pelos quatro pilares para a educação do século XXI -, a essência permanece inalterada, na qual o controle objetivo e subjetivo do trabalho cooperado, inerente à relação entre trabalho e educação, materializa o processo de racionalização do capital e consequentemente da valorização do valor. Ambas as manifestações da subsunção total do ser ao capital, calcadas no pragmatismo inerente à racionalização do capital, atuam nos trabalhadores/alunos como princípios, "palavras de ordem", que não sugerem dúvidas, mas sim certezas absolutas, processo que vai de encontro aos princípios da aplicação tecnológica da ciência voltada à emancipação e aos valores propostos pelo universo acadêmico-científico crítico pautado no questionamento e na incerteza no tocante a "verdades absolutas".

Destarte, os métodos e técnicas presentes na relação entre trabalho e educação - aqui especificamente as tecnologias gerenciais -, independente da forma assumida historicamente em acordo com o sistema de produção vigente, estão orientados à racionalização do trabalho cooperado e ao pragmatismo capitalista no que se refere à valorização do valor.

\section{REFERÊNCIAS}

Alves, Giovanni. Dimensões da reestruturação produtiva: ensaios de sociologia do trabalho. 2. ed. Londrina: Praxis; Bauru: Canal 6, 2007.

. Trabalho e subjetividade: o espírito do toyotismo na era do capitalismo manipulatório. São Paulo: Boitempo, 2011.

Battaglia, Flávio. Para que tanta tecnologia? [on-line]. São Paulo: Lean Institute Brasil, 29 maio 2005. Disponível em: <http:www.lean.org.br>. Acesso em: 25 maio 2007. 
Bianchetti, Lucídio. As novas tecnologias e o devassamento do espaço-tempo do saber tácito dos trabalhadores. In: AuEd, Bernardete Wrublevski. Educação para o (des)emprego. 2. ed. Petrópolis: Vozes, 2000. p. 133-150.

Braga, Ruy. Introdução. In: Gramsci, Antonio. Americanismo e fordismo. São Paulo: Hedra, 2008.p. 9-27.

BRUNo, Lúcia (Org.). Educação e trabalho no capitalismo contemporâneo: leituras selecionadas. São Paulo: Atlas, 1996.

Bryan, Newton Antonio Paciulli. Educação, processo de trabalho, desenvolvimento econômico: contribuição aos estudos das origens e desenvolvimento da formação profissional no Brasil. Campinas: Alínea, 2008.

Cattani, Antônio David; Holzmann, Lorena (Org.). Dicionário de trabalho e tecnologia. Porto Alegre: EdUFRGS, 2006.

Delors, Jacques. Educação: um tesouro a descobrir. 2.ed. São Paulo: Cortez; Brasilia: MEC/ UNESCO, 2003.

Dinero, Donald. Training within industry: the foundations of lean. New York: Productivity Press, 2005.

DuARTE, Newton. Vigotski e o "aprender a aprender": crítica às apropriações neoliberais e pós-modernas da teoria vigotskiana. Campinas: Autores Associados, 2001. . (Org.). Crítica ao fetichismo da individualidade. Campinas: Autores Associados, 2004. FARIA,José Henrique de (Org.). Tecnologia e processo de trabalho.2. ed. Curitiba: EdUFPR,1997. . Economia politica do poder. Curitiba: Juruá, 2004.v. I e II. . Análise crítica das teorias e práticas organizacionais. São Paulo: Atlas, 2007.

Francisco Filho, Geraldo. Administração escolar analisada no processo histórico. Campinas: Alínea, 2006.

Gramsci, Antonio. Americanismo e fordismo. São Paulo: Hedra, 2008.

Gurgel, Cláudio. A gerência do pensamento: gestão contemporânea e consciência neoliberal. São Paulo: Cortez, 2003.

Huntzinger, Jim. Treinamento dentro da induistria: a origem do gerenciamento japonês e do kaizen. [on-line]. São Paulo: Lean Institute Brasil, s.d. Disponível em: <http://www.lean.org. br>. Acesso em: 30 abr. 2007.

Justa, Marcelo Augusto Oliveira da; Barreiros, Nilson Rodrigues. Técnicas de gestão do Sistema Toyota de Produção. Gestão Industrial,Ponta Grossa:UTFPR,v. 5, n. 1, p. 1-17, 2009. Laval, Christian. A escola não é uma empresa: o neoliberalismo em ataque ao ensino público. Londrina: Editora Planta, 2004.

Liker,Jeffrey K.; Hoseus, Michael. A cultura Toyota. A alma do modelo Toyota. Porto Alegre: Bookman, 2009.

Martins, Lígia Márcia. Da formação humana em Marx à crítica da pedagogia das competências.In:DuArTe, Newton (Org.). Crítica ao fetichismo da individualidade. Campinas: Autores Associados, 2004. p. 53-74. 
Marx, Karl. Capitulo VI inédito de O Capital: resultados do processo de produção imediata. São Paulo: Editora Moraes, 1985. .; Engels, Friedrich. Textos sobre educaşão e ensino. São Paulo: Moraes, 1992.

Mészarós, István. Para além do capital: rumo a uma teoria da transição. São Paulo: Boitempo, 2002.

Onno, Taiichi. O sistema Toyota de produção: além da produção em larga escala. Porto Alegre: Bookman, 1997.

Oliveira, Eurenice de. Toyotismo no Brasil: desencantamento da fábrica, envolvimento e resistência. São Paulo: Expressão Popular, 2004.

Organização para a Cooperação e Desenvolvimento Econômico-OCDE. Panoramas sobre a educação: indicadores da OCDE. [S.1.]: OCDE, 2009. Disponível em: <http//:www. oecd.org/bookshop/>. Acesso em: 20 nov. 2009.

Pereira, Denise de Castro; Crivellari, Helena Maria Tarchi. Just-in-time bancário: uma discussão sobre a gestão de tecnologias organizacional. In: Encontro NAcional DA ANPAD, 15., 1991, Belo Horizonte. Anais... Belo Horizonte: ANPAD, 1991.v. I, p. 95-126.

Pinto, Geraldo Augusto. A máquina automotiva em suas partes: um estudo das estratégias do capital na indústria de autopeças. São Paulo: Boitempo, 2011.

RoEsLER, Vera Regina. Uma nova fase na relação entre mundo da educação e mundo do trabalho: um estudo de caso da criação da Universidade Corporativa Grande Banco.2007.256f. Dissertação (Mestrado em Educação) - Programa de Pós-Graduação em Educação,Universidade Federal de Santa Catarina, Florianópolis, 2007.

Shiroma, Eneida Oto. Mudança tecnológica, qualificação e politicas de gestão: a educação da força de trabalho no modelo japonês. 1993. 222f. Tese (Doutorado em Educação) - Programa de Pós-Graduação em Educação, Universidade Estadual de Campinas, Campinas, 1993.

TAuile, José Ricardo. Para (re) construir o Brasil contemporâneo: trabalho, tecnologia e acumulação. Rio de Janeiro: Contraponto, 2001.

Tragtenberg, Maurício. Burocracia e ideologia. 4. ed. São Paulo: Ática, 1985.

\section{SOBRE O AUTOR}

Rafael Rodrigo Mueller é doutor em educação pela Universidade Federal de Santa Catarina (UFSC). Professor da Universidade do Extremo Sul Catarinense (UNESC).

E-mail: rrmueller@ymail.com

Recebido em fevereiro de 2011

Aprovado em agosto de 2011 


\section{RAFAEL RODRIGO MUELLER}

\section{Tecnologias gerenciais, educação e capital}

O objetivo de nosso artigo é analisar as tecnologias gerenciais e sua relação histórica com a educação. Para tanto, torna-se imprescindível verificarmos a relação existente entre os métodos e técnicas de treinamento desenvolvidos nos Estados Unidos por Charles Allen, em 1919, que foram intensificados com base no que ficou conhecido como "treinamento dentro da indústria" ou Training Within Industry (TWI), em 1940, e evoluíram após a Segunda Guerra Mundial, e o que se caracterizou como "gerenciamento japonês", quando finalmente fundamentaramse como um elemento-chave do sistema Toyota de produção (STP). O caráter ideológico que perpassa e é característico das tecnologias gerenciais foi verificado por intermédio da relação de tal manifestação de tecnologia com os ideais educacionais presentes tanto no discurso de managers como nas recomendações dos órgãos multilaterais e suas determinações voltadas à educação nas últimas três décadas.

Palavras-chave: tecnologias gerenciais; trabalho e educação; capital; toyotismo.

\section{Management technologies, education and capital}

The purpose of our study is to analyze management technologies and their historical relationship with education. To this end, it is essential to verify the relationship between the training methods and techniques developed in the United States by Charles Allen in 1919, which were intensified from what became known as Training Within Industry (TWI) in 1940, and evolved after the Second World War, as well as what was characterized as "Japanese management", when they finally became a key element of the Toyota Production System (TPS). The ideological character that pervades and characterizes management technologies has been verified through the relationship of such expressions of technology with the educational ideals present in both the discourse of managers and the recommendations of multilateral agencies and their guidelines regarding education in the last three decades.

Keywords: management technologies; labor and education; capital; toyotism. 


\section{Tecnologías de gestión, educación y capital}

El objetivo de nuestro trabajo es analizar las tecnologías de gestión y su relación histórica con la educación. Para ello, es esencial verificar la relación entre los métodos y técnicas de formación desarrollados en los Estados Unidos por Charles Allen en 1919, que se intensificaron a partir de lo que se conoce como "Formación en la Industria" o de Formación Dentro de la Industria (FDI) en 1940, y evolucionaron después de la Segunda Guerra Mundial, y lo que se caracterizó como "gestión japonesa", cuando por fin se establecieron como un elemento clave del "Sistema de Producción Toyota" (SPT). El carácter ideológico presente que es característico de las tecnologías de gestión ha sido verificado a través de la relación de esas expresiones de la tecnología con los ideales educativos que se expresan tanto en el discurso de los managers como de las recomendaciones de los organismos multilaterales y sus determinaciones relacionadas con la educación en las últimas tres décadas.

Palabras clave: tecnologias de gestión; trabajo y educación; capital; toyotismo. 